\title{
Socioeconomic gradient in health and the covid-19 outbreak
}

\author{
Roger Yat-Nork Chung assistant professor ${ }^{1}$, Dong Dong research assistant professor ${ }^{1}$, Minnie Ming \\ Li lecturer ${ }^{2}$
}

${ }^{1}$ School of Public Health and Primary Care, Prince of Wales Hospital, The Chinese University of Hong Kong, Shatin, NT, Hong Kong; ${ }^{2}$ Department of Social Sciences, Faculty of Liberal Arts and Social Sciences, The Education University of Hong Kong, Hong Kong

At the time of writing [1 April 2020], there have been 859556 confirmed cases of covid-19 and 42332 deaths. ${ }^{1}$ The epidemic has so far been controlled partially by national mobilisation of healthcare resources, but shortage of resources is of grave concern in other, especially developing, countries affected later by covid-19, underscoring global health inequalities. ${ }^{2}$

Many countries are currently using a household based prevention model, which usually includes mandatory self-quarantine of people who have travelled to high risk places. This model can be fragile and limited, especially for socially disadvantaged people, who are poor, isolated, and undereducated. The wellbeing of family members can also be compromised indirectly, even if they do not get the disease. In the rural area of Hubei, a 17 year old boy with cerebral palsy, whose single father was placed in a quarantine facility for possible covid-19 infection, was found dead after six days of being left alone at home. ${ }^{3}$

The socioeconomic gradient in health can also be seen in higher socioeconomic groups. In Hong Kong, in the earlier stage of the outbreak, there was inadequate government support for healthcare professionals. A specialist had to pay out of pocket to rent a hotel room for self-quarantine to protect his family members; healthcare staff of lower ranking, however, might not be able to afford that. ${ }^{4}$ We need to be cautious of similar situations in other countries.
The socioeconomic gradient in health extends beyond people in lower socioeconomic groups to their family members and to those in higher socioeconomic positions. Attention should be focused not only on people with the disease but on a whole population health prevention strategy that promotes good public hygiene practices. Disease specific health literacy is also essential.

RY-NC is associate director of the CUHK Institute of Health Equity at the Chinese University of Hong Kong.

Competing interests: None declared.

Full response at: https://www.bmj.com/content/368/bmj.m755/rr-1.

1 Coronavirus covid-19 global cases by the Center for Systems Science and Engineering (CSSE) at Johns Hopkins University (JHU). https://www.arcgis.com/apps/opsdashboard/ index.html\#/bda7594740fd40299423467b48e9ecf6.

Abbasi K. Health inequalities: death by political means. $B M$ 2020;368:m75510.1136/bmj.m755

3 Standaert M. Disabled teenager in China dies at home alone after relatives quarantined. Guardian 2020 Jan 30. https://www.theguardian.com/world/2020/jan/30/disabled-teenagerin-china-dies-at-home-alone-after-relatives-quarantined.

4 No quarantine arrangement at the Queen Mary Hospital. After receiving confirmed case, doctor rented hotel room for self-quarantine. HK01 2020 Jan 30. https://www.hk01.com/ article/427950

Published by the BMJ Publishing Group Limited. For permission to use (where not already granted under a licence) please go to http://group.bmj.com/group/rights-licensing/ permissions 